\title{
Clinicopathological Characteristics of Atypical Teratoid/Rhabdoid Tumor
}

\author{
Hidehiro OKA*,** and Bernd W. SCHEITHAUER*
}

\begin{abstract}
*Department of Laboratory Medicine and Pathology, Mayo Clinic and Mayo Foundation, Rochester, Minnesota, U.S.A; ** Department of Neurosurgery, Kitasato University School of Medicine, Sagamihara, Kanagawa
\end{abstract}

\begin{abstract}
The clinicopathological features of atypical teratoid/rhabdoid tumor, a new entity among malignant pediatric brain tumors, and the differential diagnosis from primitive neuroectodermal tumor (PNET)/ medulloblastoma, and germ cell tumor are described. Histologically, atypical teratoid/rhabdoid tumor is defined as a polymorphous neoplasm often featuring rhabdoid, PNET, epithelial, and mesenchymal components. Atypical teratoid/rhabdoid tumors usually include PNET components and occur mainly in the posterior fossa, so mimic medulloblastoma. Atypical teratoid/rhabdoid tumor is characterized by the cytogenetic finding of monosomy 22 rather than $i(17 q)$. The tumor is similarly mistaken for PNET at supratentorial sites. Germ cell tumors also enter into the differential diagnosis due to their histological immunophenotypic diversity, particularly features indicative of epithelial and mesenchymal differentiation. Nonetheless, the remarkable spectrum of tissues that typify teratoma is absent in atypical teratoid/rhabdoid tumor. The same is true of germ cell marker in tumor tissues and serum. The prognosis of atypical teratoid/rhabdoid tumor is far less favorable than that of PNET/medulloblastoma of malignant or germ cell tumor. Meta-analysis of 133 cases, including 15 new and 118 reported cases, confirm that atypical teratoid/rhabdoid tumor is as a clinicopathological entity and emphasizes the necessity for distinguishing this unique tumor from other pediatric central nervous system neoplasms.
\end{abstract}

Key words: atypical teratoid/rhabdoid tumor, medulloblastoma, primitive neuroectodermal tumor, germ cell tumor

\section{Introduction}

Cerebellar medulloblastoma and other primitive neuroectodermal tumors (PNETs) of the central nervous system (CNS) are presumably variants of the same tumor type, and are among the most biologically malignant of pediatric brain tumors. ${ }^{16,22,53)}$ Several subtypes have been described, some of which are morphologically distinctive. ${ }^{11\}}$

Malignant rhabdoid tumors were originally described as a renal neoplasm of infancy or childhood, and consist of large, monomorphous, relatively noncohesive cells with vesicular nuclei, prominent nucleoli, and characteristic cytoplasmic filament inclusions. ${ }^{3,42]}$ These tumors may arise in the kidney or at a variety of other sites, and are associated with an extremely poor prognosis. ${ }^{421}$ To date, more than 70 cases of malignant rhabdoid

Received September 11, 1998; Accepted March 27, 1999 tumors of the CNS have been reported, $^{1,2,4,5,7,9,10,13,15,23,27,28,30-37,40,41,44,45,51,54,56-59)} 19$ (28\%) in association with malignant rhabdoid tumors of the kidney or liver. $8,12,14,17-21,29,38,39,46,52)$

In 1987, a distinctive brain tumor occurring in young children was described with epithelial and mesenchymal elements, but lacking the broad morphological spectrum, immunohistochemical profile, and serum markers associated with germ cell tumors. ${ }^{35)}$ This tumor was originally designated "atypical teratoid tumor," but the frequent presence of a rhabdoid component prompted a renaming to "atypical teratoid/rhabdoid tumor of infancy and children." ${ }^{\text {"7.48] }}$ Since the majority of atypical teratoid/rhabdoid tumors arise in the posterior fossa and include primitive neuroectodermal components with immunoreactivity for neuronal and glial antigens, they are easily mistaken for the PNET/medulloblastoma type. Few malignant rhabdoid tumors or atypical teratoid/rhabdoid tumor have been reported in Japan. ${ }^{39,51,55,56)}$ As a result, the entity is un- 
familiar and not entirely accepted.

Here, we describe the clinicopathological features of atypical teratoid/rhabdoid tumor found in a series of 15 cases and a meta-analysis of the 118 cases reported to date, in order to stress the distinction of atypical teratoid/rhabdoid tumor from PNET/ medulloblastoma as well as germ cell tumors, which are diseases with markedly different therapies and outcomes.

\section{Materials and Methods}

The definition of atypical teratoid/rhabdoid tumors is a cellular neoplasm consisting of sheets of neoplastic briskly mitotic cells, often interrupted by fibrovascular septa and necrosis; markedly varying numbers of large rhabdoid cells with vesicular nuclei, prominent nucleoli, and spherical cytoplasmic filamentous inclusions; pale cell, which are similar but more cohesive and lacking inclusions; often prominent, typical PNET components; mesenchymal cells commonly with spindle or chondroid features; and epithelial components. ${ }^{48)}$ The immunoprofile of atypical teratoid/rhabdoid tumor is therefore complex and includes epithelial (keratin, epithelial membrane antigen), neuroectoderm (synaptophysin, glial fibrillary acidic protein: GFAP), and mesenchymal (smooth muscle actin, desmin) markers. ${ }^{10,11,48)}$

The clinicopathological features of 15 previously unpublished cases of atypical teratoid/rhabdoid tumor from the consultation files of one of us (B.W.S.), and data from 118 published cases of atypical teratoid/rhabdoid tumor were subjected to meta-analysis, including 52 cases from a large series, ${ }^{48} 11$ case reports or short series, , $, 26,31,35-37,45,47-50,55]$ and 55 recently reported cases from the Pediatric Oncology Group. ${ }^{103}$ Clinical features subject to analysis included patient age and sex at presentation, symptoms, neurological signs, tumor location and stage, type of therapy, and response, as well as eventual outcome.

\section{Results}

\section{Clinical findings}

The 133 patients were aged from 22 days to 14.9 years (median 2.1 years): 120 patients (90\%) were younger than 5 years, and over $75 \%$ were younger than 3 years. Nine patients $(7 \%)$ were between ages 6 and 10 years, and only four [3\%) between 11 and 15 years. There was a 1.5:1 male predominance.

The clinical symptoms were related to tumor location and were usually non-specific in nature. The principal symptoms were vomiting, headache, and lethargy.

Of the 133 tumors, $81(61 \%)$ were located in the posterior fossa, $27(20 \%)$ in the cerebral hemispheres, seven $(5 \%)$ in the suprasellar and/or third ventricular regions, seven $(5 \%)$ in the pineal region, and one $(1 \%)$ in the spinal cord. Seven patients (5\%) apparently had multifocal lesions at presentation. Tumor location was unstated in the remaining three cases. The majority of tumors arose in the cerebellum or nearby ventricular system. Analysis of patient age and tumor location found $67 \%$ of the patients younger than 5 years had posterior fossa tumors. In contrast, $85 \%$ of those over 6 years of age arose in the cerebral hemispheres, and only $15 \%$ were infratentorial.

\section{Stage at presentation}

Cerebrospinal fluid (CSF) examination at presentation in 29 of 55 cases found that nine (31\%) were positive for malignant cells. ${ }^{10)}$ Preoperative myelography in 31 of these 55 cases found eight had metastatic disease, but only five of these eight had positive CSF cytology. Adequate evaluation for disseminated disease at diagnosis in 41 of $\mathbf{5 2}$ patients found 14 tumors (34\%) had undergone leptomeningeal dissemination. ${ }^{48)}$ In total, information regarding leptomeningeal dissemination at diagnosis or first recurrence was available in 114 cases, ${ }^{10,31,37,48,50}$ and $75(66 \%)$ presented with disseminated tumor at diagnosis or first recurrence.

\section{Radiological findings}

The radiological features of atypical teratoid/ rhabdoid tumor resembled those of cerebral PNET and medulloblastoma. ${ }^{47,48)}$ Computed tomography showed the tumor as iso- to hyperdense with inhomogeneous enhancement after contrast administration. Cysts and hemorrhages were common and some tumors showed nodular calcification. Magnetic resonance imaging usually revealed mixed intensity on $T_{1}$-weighted images and iso- to hyperintensity on $T_{2}$-weighted images, with inhomogeneous enhancement on gadoliniumdiethylenetriaminepenta-acetic acid administration. Atypical teratoid/rhabdoid tumors tended to be large, relatively demarcated masses; supratentorial lesions were occasionally huge. Variable peritumoral edema was often present.

\section{Treatment}

All tumors were approached by stereotactic biopsy or craniotomy. The patients underwent biopsy or partial resection in 41 of 63 described cases $(65 \%)$ and subtotal resection or gross total resection in $22(35 \%)$. Postoperative adjuvant ther- 
apy in 83 cases involved chemotherapy in 66 patients $(80 \%)$ at the time of diagnosis. Understandably, a wide variety of agents and regimens were used, particularly combinations of VP-16 and cisplatinum. Thirty-two patients (38\%) underwent radiotherapy, with or without chemotherapy.

\section{Outcome}

At the time of this analysis, 98 of the 133 patients $(74 \%)$ had died of local and/or disseminated disease, within 3 days to 24 months of diagnosis (mean 8.5 months).

Previously, six (17\%) of 33 children who underwent postoperative chemotherapy and three who received preirradiation chemotherapy had experienced a greater than $50 \%$ reduction in tumor mass, including two patients who had received the augmented "baby POG" regimen (cyclophosphamide, vincristine, cisplatinum, and VP16), one who had undergone eight-drug-in-one-day therapy, two on an alternative cisplatinum regimen, and one who had received combined high-dose cyclophosphamide and VP-16. ${ }^{48)}$ Despite postoperative adjuvant therapy, the longest lasting response to chemotherapy was 24 months. The median overall survival time was 8.5 months in this study. In author series, 49 of 52 patients developed progressive disease: 23 at the primary site, nine at the primary site with cranial metastases, and 16 with craniospinal metastases unaccompanied by local recurrence. ${ }^{10)}$ At the end of follow-up period, 41 patients were dead of disease. The mean interval between initial surgery and death was $11 \pm 13$ months. Among four patients, one child treated prior to the availability of bone marrow transplantation died of progressive disease 9 months after diagnosis; another child treated with high-dose chemotherapy and radiotherapy in preparation for bone marrow transplant experienced a recurrence and died 20 months after diagnosis; and two others underwent high-dose chemotherapy and autologous bone-marrow transplantation and had a relatively good response. ${ }^{26)}$

\section{Histological findings}

Atypical teratoid/rhabdoid tumor was characterized by the rhabdoid cells typical of malignant rhabdoid tumor. Large cells and possessing eccentric vesicular nuclei with a prominent nucleolus as well as an intracytoplasmic hyaline inclusion may be scant (Fig. 1A). Sheets of large, so-called "pale" cells with similar central or eccentric nuclei but lacking inclusions were common (Fig. 1B). Cell transitions between pale and the typical rhabdoid cells were occasionally seen. Such neoplastic cells with large nuclei and prominent nucleoli may su- perficially resemble neurons.

Tissue resembling PNET/medulloblastoma is a very common feature of atypical teratoid/rhabdoid tumor and was present in $67 \%$ of cases, ${ }^{48]}$ characterized by small cells with indistinct outlines, sparse cytoplasm, and dense nuclei with dispersed chromatin and frequently small nucleoli (Fig. 1C). Such cells were typically arranged in a nested pattern within a delicate fibrovascular stroma. Although vague nodularity was occasionally encountered, the overt pale islands so typical of "desmoplastic medulloblastoma" were not present.

Cells with epithelial features are reportedly present in $25 \%$ of cases. ${ }^{48)}$ In most instances, such cells featured gland-like spaces arrangements (Fig, 1D) and were sometimes associated with a hyalinized and/or mucoid matrix (Fig. 1E). A squamous component was noted in $2 \%$ of cases. ${ }^{48]}$ Spindle cells resembling mesenchyme were less frequent (Fig. 1F). No mention has been made of specialized mesenchymal elements such as cartilage, bone, or muscle.

\section{Immunohistochemical findings}

In all 126 cases studied, immunohistochemical staining showed diffuse express ion of vimentin with nearly uniform reactivity. Both rhabdoid and epithelial cells were immunoreactive for epithelial membrane antigen in 130 of 131 cases (99\%), and cytokeratin in 97 of 127 cases (76\%). PNET and rhabdoid pale cell areas showed reactivity for GFAP in 96 of 131 cases (73\%) and for synaptophysin in 41 of 131 cases (31\%). Rhabdoid cells/pale cells and scattered spindle cells were weakly positive for smooth muscle actin in 98 of 123 cases (80\%) and for desmin in $20 \%$. Despite obvious divergent differentiation, particularly the presence of epithelial and mesenchymal tissues in some tumors, germ cell markers such as human chorionic gonadotropin and placental alkaline phosphatase were generally negative. Only one series found limited alpha-fetoprotein staining was in eight of nine cases. ${ }^{9)}$ The significance of the latter is unknown, and the finding awaits confirmation.

\section{Ultrastructural features}

Understandably, the ultrastructural features of atypical teratoid/rhabdoid tumor varied and subject and to tissue sampling. ${ }^{4,48}$ Rhabdoid cells in which varying accumulations of whorled intermediate filament bundles often displaced nuclei were readily identified (Fig. 2). Some had irregular, deep indented nuclei whereas others were binucleate. Epithelial cells formed nests separated from the stromal elements by basement membrane material. Frequently, 


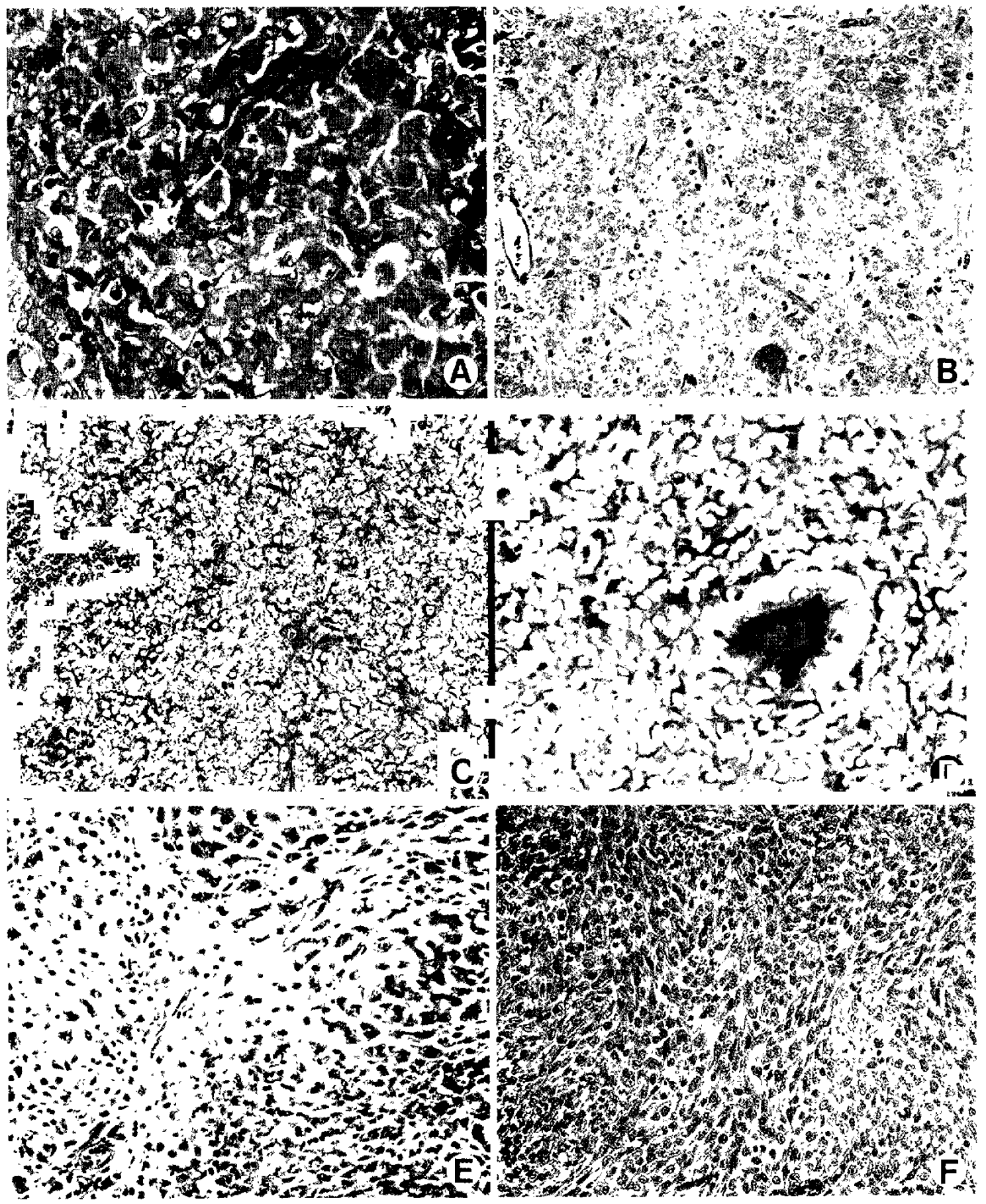

Fig. 1 Photomicrographs of a specimen of atypical teratoid/rhabdoid tumor showing typical malignant rhabdoid cells (A: HE stain, $\times 400$ ). The cells are large and possess eccentric vesicular nuclei containing a prominent nucleolus, with intracytoplasmic hyaline inclusions. The so-called "pale" cells possess central or eccentric nuclei similar to those of rhabdoid cells but lack cytoplasmic inclusions $(B:$ HE stain, $\times 200$ ). Small cell components resembling primitive neuroectodermal tumor/medulloblastoma are common, and feature dense nuclei with dispersed chromatin and small nucleoli, scant cytoplasm, and indistinct cell outlines (C: HE stain, $\times \mathbf{2 0 0}$ ). Epithelial differentiation is less frequent and may take the form of occasional glands (D: HE stain, $\times 400$ ). Clusters of epithelioid cells occasionally lie in mucoid to hyalinized matrix (E: HE stain, $\times 200$ ). Spindled cells resembling mesenchymal cells may also occur (F: HE stain, $\times \mathbf{2 0 0}$ ). 


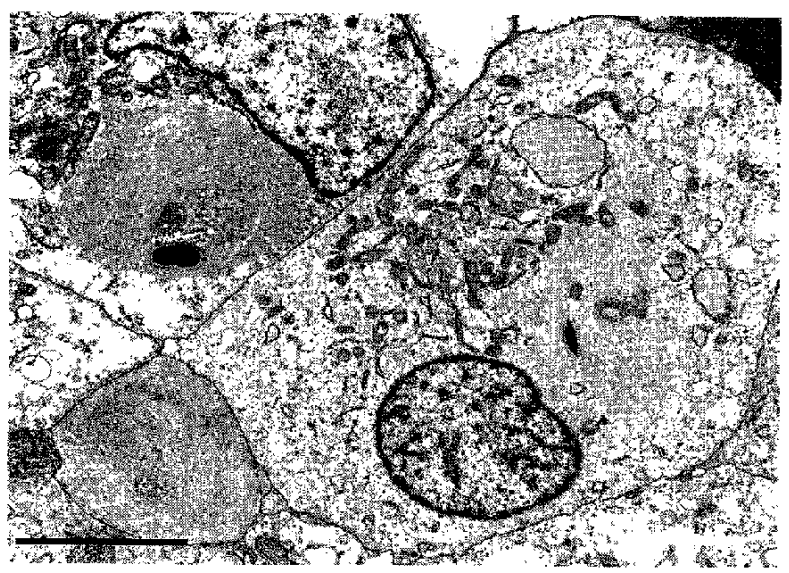

Fig. 2 Electron micrograph of rhabdoid cells showing their large size, scant organelles, and intermediate filament whorls that often indent the nucleus. Bar $=1 \mu \mathrm{m}$.

intermediate filaments were present in the cytoplasm. PNET regions contained small cells in a background of abundant cell processes. The latter contained small dense core granules and neurofilaments. Poorly differentiated mesenchymal cells were occasionally found.

\section{Cytogenetic examination}

Fifty-five $(74.3 \%)$ of the 74 atypical teratoid/rhabdoid tumor specimens analyzed for chromosome abnormalities showed monosomy of chromosome 22. In another series, five of nine tumors studied showed an abnormality of chromosome 22 or with monosomy 22 and four with partial deletions of chromosome $22 .{ }^{48)}$ In each of these four instances, the deletion resulted from a break in the region of 22q11. In one case, a karyotype revealed loss of chromosomes 6 and 13 as well as deletion of the distal short arm of chromosome 22. In contrast, although a small number of PNET/medulloblastomas have shown monosomy 22, by far the most common abnormality in CNS PNETs is an $\mathrm{i}(17 \mathrm{q})$ which is present in $50 \%$ of cases. ${ }^{6}$

\section{Discussion}

Although medulloblastomas occur at all ages from the newborn to the seventh decade, but most commonly arise in the first decade between 5 and 8 years, fully $70 \%$ of tumors occur in patients less than 8 years of age. ${ }^{53)}$ Extracerebellar PNETs are also characterized by their predominance in early life, with a median age of 3 to 8 years. ${ }^{16,47}$ Atypical teratoid/rhabdoid tumors generally arise earlier in life compared to medulloblastomas and extracerebellar PNETs.

The 5-year survival of patients with medulloblastomas treated by adjuvant therapy varies from $25 \%$ and $70 \%{ }^{53)}$ Patients with extracerebellar PNET generally survive less than 24 months in spite of surgery, radiotherapy, and chemotherapy. ${ }^{16)}$ Atypical teratoid/rhabdoid tumor appears to be relatively nonresponsive to adjuvant therapies. The same is true of systemic malignant rhabdoid tumor, although occasional examples respond to a protocol for rhabdomyosarcoma. ${ }^{43)}$ Although the two largest series of atypical teratoid/rhabdoid tumor report poor responses, two patients who received highdose chemotherapy and autologous bone-marrow transplant had a relatively good response. ${ }^{26)}$ At present, there is no generally accepted treatment for atypical teratoid/rhabdoid tumor. ${ }^{47,4 a)}$

Atypical teratoid/rhabdoid tumors are among the most malignant of CNS tumors. The prognosis is far poorer than that of medulloblastoma, and perhaps that of PNET as well. The lack of therapeutic response and dismal prognosis requires that atypical teratoid/rhabdoid tumor be distinguished from tumors of the PNET/medulloblastoma group. Cellular neoplasms arising in the cerebellum of infants and children naturally suggest the differential diagnosis of medulloblastoma. Indeed, this was the initial diagnosis in almost all previous cases of posterior fossa atypical teratoid/rhabdoid tumors. ${ }^{10,31,48)}$ However, there are radiological clues to the diagnosis such as cyst formation or calcification, as well as the microinvasive histological characteristics. In contrast to medulloblastoma, atypical teratoid/rhabdoid tumor has a high incidence of necrosis with calcification as well as frequent broad fibrovascular septae. The presence of large epithelial and/or mesenchymal cells also indicate a diagnosis of atypical teratoid/rhabdoid tumor. ${ }^{10)}$ Obviously, the distinction may be difficult in a small or nonrepresentative biopsy featuring only the small cell component. In such instances, the application of a panel of immunohistochemical stains is the optimal approach.

In terms of cell size and aggressiveness, some atypical teratoid/rhabdoid tumors resemble the socalled "large cell" variant of medulloblastoma, which is histologically characterized by sheets of large cells as monomorphous, or more so, than those occurring in atypical teratoid/rhabdoid tumor, with similarly round and more regular nuclei. Large cell medulloblastomas lack epithelial and myoid markers. Although both tumors show synaptophysin reactivity, neurofilament protein staining is more frequently widespread in large cell medulloblastoma 
than in atypical teratoid/rhabdoid tumor.

Renal rhabdoid tumors typically show deletions and/or translocation of chromosome 22. Loss of heterozygosity was identified in $80 \%$ of tumors in a common region at 22q11.2-22q12.2. Cytogenetic analyses of purely rhabdoid tumors of the CNS similarly demonstrate abnormalities of chromosome $22,{ }^{5,6,24,25)}$ but CNS rhabdoid tumors more often show monosomy. ${ }^{10)}$ The contention that atypical teratoid/ rhabdoid tumors are teratomatous in nature is not supported by chromosome analysis. Topographic and histological observations also refute this concept as atypical teratoid/rhabdoid tumors show no predilection for the pineal and suprasellar regions, typical sites of intracranial germ cell neoplasms. Furthermore, they lack the well-differentiated glioneuronal and specialized respiratory/gastrointestinal tissues so commonly seen in teratomas as well as germ cell marker immunoreactivities. ${ }^{103}$

Atypical teratoid/rhabdoid tumor is a distinct tumor of young children based on morphological, immunohistochemical, and cytogenetic characteristics. The majority of atypical teratoid/rhabdoid tumor are infratentorial, and mimic medulloblastoma. Atypical teratoid/rhabdoid tumor is similarly mistaken for PNET at supratentorial sites. Germ cell tumors are also part of the differential diagnosis, but immunoreactivity for germ cell tumor markers, with the possible exception of occasional granular alphafetoprotein staining, is typically negative. The same is true of CNS investigations. Atypical teratoid/ rhabdoid tumor is refractory to PNET and germ cell chemotherapy, so the prognosis is much less favorable than that of PNET/medulloblastoma or germ cell tumors.

\section{Acknowledgments}

This work was supported in part by a Grant-in-Aid for Scientific Research (Nos. 08671611 and 10877218) and an Academic Frontier Project from the Japanese Ministry of Education, Science, Sports and Culture, as well as the Parents' Association Grant of Kitasato University School of Medicine, Sagamihara, Kanagawa, Japan.

\section{References}

1) Agranovich AL, Ang LC, Griebel RW, Kobrinsky NL, Lowry N, Tchang SP: Malignant rhabdoid tumor of the central nervous system with subarachnoid dissemination. Surg Neurol 37: 410-414, 1991

2) Ashraf R, Bentley RC, Awan AN, McLendon RE, Ragozzino MW: Implantation metastasis of primary malignant rhabdoid tumor of the brain in an adult (one case report). Med Pediatr Oncol 28: 223-227, 1997

3) Beckwith JB, Palmer NF: Histopathology and prognosis of Wilms' tumor. Results from the First National Wilms' Tumor Study. Cancer 41: 1937-1948, 1978

4) Bhattacharjee M, Hicks J, Langford L, Dauser R, Strother D, Chintagumpala M, Horowitz M, Cooley L, Vogel H: Central nervous system atypical teratoid/rhabdoid tumors of infancy and childhood. Ultrastruct Pathol 21: 369-378, 1997

5) Biegel JA, Burk CD, Parmiter AH, Emanuel BS: Molecular analysis of a partial deletion of $22 \mathrm{q}$ in a central nervous system rhabdoid tumor. Genes Chromosomes Cancer 5: 104-108, 1992

6] Biegel JA, Rorke LB, Packer RJ, Emanuel BS: Monosomy 22 in rhabdoid or atypical tumors of the brain. J Neurosurg 73: 710-714, 1990

7) Biggs PJ, Garen PD, Powers JM, Garvin AJ: Malignant rhabdoid tumor of the central nervous system. Hum Pathol 18: 332-337, 1987

8) Bonnin JM, Rubinstein LJ, Palmer NF, Beckwith JB: The association of embryonal tumors originating in the kidney and in the brain. A report of seven cases. Cancer 54: 2137-2146, 1984

9) Briner J, Bannwart F, Kleihues P, Odermatt B, Janzer R, Willi U, Boltshauser E: Malignant small cell tumor of the brain with intermediate filaments - a case of a primary cerebral rhabdoid tumor. Pediatr Pathol 3: $117-118,1985$

10) Burger P, Yu IT, Tihan T, Friedman HS, Strother DR, Kepner JL, Duffner PK, Kun LE, Perlman EJ: Atypical teratoid/rhabdoid tumor of the central nervous system: A highly malignant tumor of infancy and childhood frequently mistaken for medulloblastoma. A pediatric oncology group study. Am J Surg Pathol 22: 1083-1092, 1998

11) Burger PC, Scheithauer BW: Tumors of central nervous system, in: Atlas of Tumor Pathology, third series, fascicle 11. Washington, DC, AFIP, 1993, pp 245-247

12) Chang $\mathrm{CH}$, Ramirez N, Sakr WA: Primitive neuroectodermal tumor of the brain associated with malignant rhabdoid tumor of the liver: a histologic, immunohistochemical, and electron microscopic study. Pediatr Pathol 9: 307-319, 1989

13) Chou SM, Anderson IS: Primary CNS malignant rhabdoid tumor (MRT): report of two cases and review of literature. Clin Neuropathol 10: 1-10, 1993

14) Cohn RD, Frank Y, Stanek AE, Kalina P: Malignant rhabdoid tumor of the brain and kidney in a child: clinical and pathologic features. Pediatr Neurol 13: 65-68, 1997

15] Cossu A, Massarelli G, Manetto V, Viale G, Tanda F, Bosincu L, Iuzzolino P, Cossu S, Padovani R, Eusebi V: Rhabdoid tumours of the central nervous system. Report of three cases with immunocytochemical and ultrastructural findings. Virchows Arch A Pathol Anat Histopathol 422: 81-85, 1993

16) Crain B: Primitive neuroectodermal tumors, in 
Wilkins RH, Rengachary SS (eds): Neurosurgery, ed 2, vol II. New York, McGraw-Hill, 1996, pp 1707-1712

17) De Chadarévian JP, Vekemans $M$, Bernstein $M$ : Fanconi's anemia, medulloblastoma, Wilms' tumor, horseshoe kidney, and gonadal dysgenesis. Arch Pathol Lab Med 109: 367-369, 1985

18) Ehret M, Jacobi G, Hey A, Segerer S: Embryonal brain neoplasm in the neonatal period and early infancy. Clin Neuropathol 6: 218-223, 1987

19) Fisher BJ, Siddiqui J, Macdonald D, Cairney AE, Ramsey D, Munoz D, Del Maestro R: Malignant rhabdoid tumor of brain: an aggressive clinical entity. Can J Neurol Sci 23: 257-263, 1996

20) Fort DW, Tonk VS, Tomlinson GE, Timmons CF, Schneider NR: Rhabdoid tumor of the kidney with primitive neuroectodermal tumor of the central nervous system: associated tumors with different histologic, cytogenetic and molecular findings. Genes Chromosomes Cancer 11: 146-152, 1994

21) Gansler T, Gerald W, Anderson G, Gramling TS, Williams CH, Sens D, Garvin AJ: Characterization of a cell line derived from rhabdoid tumor of kidney. Hum Pathol 22: 259-266, 1991

22) Haas JE, Palmer NF, Weinberg AG, Beckwith JB: Ultrastructure of malignant rhabdoid tumor of the kidney. A distinctive renal tumor of children. Hum Pathol 12: 646-657, 1981

23) Hanna SL, Langston JW, Parham DM, Douglass EC: Primary malignant rhabdoid tumor of the brain: clinical, imaging, and pathologic findings. AJNR Am J Neuroradiol 14: 107-115, 1993

24) Hasserjian RP, Folkerth RD, Scott RM, Schofield DE: Clinicopathologic and cytogenetic analysis of the central nervous system. J Neurooncol 25: 193-203, 1995

25) Hasserjian RP, Schofield D, Folkerth RF: Malignant rhabdoid tumor (MRT) of the central nervous system. J Neuropathol Exp Neurol 51: 367, 1992

26) Hilden JM, Watterson J, Longee DC, Moertel CL, Dunn ME, Kurtzberg J, Scheithauer BW: Central nervous system atypical teratoid/rhabdoid tumor: response to intensive therapy and review of the literature. J Neurooncol (in press)

27) Ho PSP, Lee WH, Chen CY, Chou TY, Wang YC, Sun M], Liou WY: Primary malignant rhabdoid tumor of the brain: CT characteristics. J Comput Assist Tomogr 14: 461-463, 1990

28) Horn M, Schlote W, Lerch KD, Steudel WI, Harms D, Thomas E: Malignant rhabdoid tumor: primary intracranial manifestation in an adult. Acta Neuropathol (Berl) 83: 445-448, 1992

29) Howat AJ, Gonzalez MF, Waters KD, Campbell PE: Primitive neuroectodermal tumour of the central nervous system associated with malignant rhabdoid tumour of the kidney: report of a case. Histopathology 19: 643-650, 1986

30) Jakate SM, Marsden HB, Ingram L: Primary rhabdoid tumour of the brain. Virchows Arch A Pathol Anat Histopathol 412: 393-397, 1988

31) Jay V, Edwards V, Halliday W, Rutka J, Lau R:
"Polyphenotypic" tumors in the central nervous system: Problems in nosology and classification. Pediatr Pathol Lab Med 17: 369-389, 1997

32) Kapur S, Patterson K, Chandra R: Primary rhabdoid tumor in the cerebellum. Pediatr Pathol 5: 101, 1986

33) Kepes JJ, Moral LA: Malignant rhabdoid tumors (MRT-S) of the central nervous system (CNS) and their morphological features seen in other CNS neoplasms. J Neuropathol Exp Neurol 50: 362, 1991

34) Kodet R, Newton WA Jr, Sachs N, Hamoudi AB, Raney RB, Asmar L, Gehan EA: Rhabdoid tumors of soft tissues: a clinicopathologic study of 26 cases enrolled in the Intergroup Rhabdomyosarcoma study. Hum Pathol 22: 674-684, 1991

35) Lefkowitz IB, Rorke LB, Packer RJ, Sutton LN, Siegel KR, Katnick RJ: Atypical teratoid tumor of infancy: definition of an entity. Ann Neurol 22: 448-449, 1987

36) Manhoff DT, Rorke LB, Yachnis AT: Primary intracranial atypical teratoid/rhabdoid tumor in a child with Canavan disease. Pediatr Neurosurg 22: 214222, 1995

37) Mart nez-Lage JF, Nieto A, Sola J, Domingo R, Costa TR, Poza M: Primary malignant rhabdoid tumor of the cerebellum. Childs Nerv Syst 13: 418-421, 1997

38) Misugi K, Yagishita S, Koyama S: An infant with medulloblastoma and Wilms' tumor. Yokohama Med Bull 28: 39-43, 1977

39) Morizane A, Nakahara I, Takahashi J, Ishikawa $M$, Kikuchi H: [A malignant rhabdoid tumor appearing simultaneously in the kidney and the brain of an infant: case report]. No Shinkei Geka 25: 665-669, 1997 (Jpn, with Eng abstract)

40) Muller M, Hubbard SL, Fukuyama K, Dirks P, Matsuzawa K, Rutka JT: Characterization of a pineal region malignant rhabdoid tumor. Toward understanding brain tumor cell invasion. Pediatr Neurosurg 22: 204-209, 1995

41) Munoz A, Carrasco A, Munoz MJ, Esparza J: Cranial rhabdoid tumor with marginal tumor cystic component and extraaxial extension. AJNR Am J Neuroradiol 16: 1727-1728, 1995

42) Murphy WM, Beckwith JB, Farrow GM: Rhabdoid tumor in tumors of the kidney, bladder, and related urinary structures, in: Atlas of Tumor Pathology, third series, fascicle 11. Washington, DC, AFIP, 1993, pp 82-89

43) Olson TA, Bayar E, Kosnik E, Hamoudi AB, Klopfenstein KJ, Pieters RS, Ruymann FB: Successful treatment of disseminated central nervous system malignant rhabdoid tumor. J Pediatr Hematol Oncol 17: 71-75, 1995

44) Parham DM, Weeks DA, Beckwith JB: The clinicopathologic spectrum of putative extrarenal rhabdoid tumors. An analysis of 42 cases studied with immunohistochemistry or electron microscopy. Am J Surg Pathol 18: 1010-1029, 1994

45) Perilongo G, Sutton L, Czaykowski D, Gusnard D, Biegel J: Rhabdoid tumor of the central nervous system. Med Pediatr Oncol 19: 310-317, 1991

46) Roggendof W: Primitive neuroectodermal tumor 
with focal rhabdoid component: a case report. Clin Neuropathol 10: 106, 1991 (abstract)

47) Rorke LB, Packer R, Biegel J: Central nervous system atypical teratoid/rhabdoid tumors of infancy and childhood. J Neurooncol 24: 21-28, 1995

48) Rorke LB, Packer RJ, Biegel JA: Central nervous system atypical teratoid/rhabdoid tumors of infancy and childhood: definition of an entity. J Neurosurg 85: 56-65, 1996

49) Rorke LB, Packer RJ, Schut L, Sutton LN, Dulaime AC: Atypical teratoid/rhabdoid tumors and the socalled 'large cell medulloblastoma.' Pediatr Neurosurg 19: 287, 1993

50) Rubio A: March $1997-4$ year old girl with ring chromosome 22 and brain tumor. Brain Pathol 7: 1027-1028, 1997

51) Satoh H, Goishi J, Sogabe T, Uozumi $T$, Kiya $K$, Migita K: Primary malignant rhabdoid tumor of the central nervous system: case report and review of literature. Surg Neurol 40: 429-434, 1993

52) Schmidt D, Leuschner I, Harms D, Sprenger E, Schafer HJ: Malignant rhabdoid tumor. A morphological and flow cytometric study. Pathol Res Pract 184: 202-210, 1989

53) Schut L, Bruce DA, Sutton LN: Medulloblastomas, in Wilkins RH, Rengachary SS (eds): Neurosurgery, ed 2, vol I. New York, McGraw-Hill, 1996, pp 1177-1181

54) Sotelo-Avila C, Gonzalez-Crussi $F$, deMello $D$, Vogler C, Gooch WH 3d, Gale G, Pena R: Renal and extrarenal rhabdoid tumors in children: a clinicopathologic study of 14 patients. Semin Diagn Pathol 3: 151-163, 1986

55) Utsuki S, Kawano N, Oka H, Saegusa H, Fujii K, Yagishita S, Scheithauer BW: [Atypical teratoid/ rhabdoid tumor; case report]. No Shinkei Geka Journal 7: 507-512, 1998 (Jpn, with Eng abstract)

56) Utsunomiya A, Shirane R, Kon H, Yoshimoto T: [A case of malignant rhabdoid tumor in the pineal region in early infancy]. No Shinkei Geka 25: 809813, 1997 (Jpn, with Eng abstract)

57) Velasco ME, Brown JA, Kini J, Ruppert ES: Primary congenital rhabdoid tumor of the brain with neoplastic hydranencephary. Childs Nerv Syst 9: 185190, 1993

58) Weeks DA, Malott RL, Zuppan CW, Liwnicz BH, Beckwith JB: Primary cerebral tumor with rhabdoid features: a case of phenotypic rhabdoid tumor of the central nervous system. Ultrastruct Pathol 18: 23-28, 1994

59) Wilson D, Dempsey RJ, John WJ: Rhabdoid tumor of the conus medullaris. I Neuropathol Exp Neurol 49: 339,1990

Addresses reprint requests to: H. Oka, M.D., Department of Neurosurgery, Kitasato University School of Medicine, 1-15-1 Kitasato, Sagamihara, Kanagawa 228-8555, Japan; B. W. Scheithauer, M.D., Department of Laboratory Medicine and Pathology, Mayo
Clinic and Mayo Foundation, 200 First Street SW, Rochester, MN 55905, U.S.A.

\section{Commentary}

The authors analyzed clinicopathological findings and meta-analysis of their 15 cases and 118 reported cases of atypical teratoid/rhabdoid tumor (AT/RT). Atypical AT/RT is a new entity among malignant pediatric tumors. It is difficult to diagnose AT/RT histologically, and these tumors usually include PNET or medulloblastoma. AT/RTs were composed of small cells resembled medulloblastoma, occasionally had cords of cells in a mucinous background like chordoma, histologically. Large, pale cells were conspicuous in a jumbled architectural arrangement, with somewhat rhabdoid appearance. Immunohistochemical staining showed polyphenotypic immunoreactivity with EMA, GFAP, VIM, cytokeratin, synaptophysin, chromogranin, and smooth muscle actin. Because this review is well analyzed in detail, the clinicopathological findings of 15 cases summarized in 133 cases were not shown. Biegel et al. showed the mutation of tumor suppressor gene in 18 examples of AT/RTs. Germ-line mutation was recognized in four examples. Though AT/RT has been diagnosed as PNET or medulloblastoma, we can think about this tumor entity with this example which does not respond to the various treatments. One of the reasons why the treatment record of medulloblastoma in Japan is not so good can be thought to be the mistaken diagnosis of this tumor. We should re-examine cases that will be diagnosed as medulloblastoma or PNET from now on in detail. Because continued research on these tumors seems to be promising, reviews such as this are important for neuropathologists and neurooncologists.

\section{References}

1) Biegel JA, Zhou JY, Rorke LB, Stentrom $C$, Wainwright LM, Fogelgren B: Germ-line and acquired mutations of INI 1 in atypical teratoid and rhabdoid tumors. Cancer Res 59: 74-79, 1999

2) Burger PC, Yu IY, Tihan T, Friedman HS, Strother DR, Kepner JL, Duffner PK, Kun LE, Perlman EJ: Atypical teratoid/rhabdoid tumor of the central nervous system: a highly malignant tumor of infancy and childhood frequently mistaken for medulloblastoma: a Pediatric Oncology Group study. Am J Surg Pathol 22: 10831092, 1998

3) Yachins AT, Neubauer D, Muir D: Characterization of a primary central nervous tumor atypical teratoid/rhabdoid tumor and derivative cell line: immunophenotype and neoplastic properties. J Neuropathol Exp Neurol 57: 961-971, 1998

Osami Kubo, M.D. 


\section{Department of Neurosurgery Neurological Institute Tokyo Women's Medical University Tokyo, Japan}

The authors analyzed and reviewed the clinicopathological characteristics of 133 atypical teratoid/rhabdoid tumors, including 15 their own and 118 reported cases, which is a newly described brain tumor mostly occurring in the posterior fossa of young children. The authors extensively reviewed the clinical, histopathological, immunohistochemical findings and ultrastructural features as well as cytogenetic examinations of this tumor. The authors emphasized the close pathological similarity of this tumor to PNET, medulloblastoma or germ cell tumor, and the necessity for distinguishing atypical teratoid/rhabdoid tumor from these tumors. This means that past cases diagnosed as PNET, medulloblastoma or germ cell tumors should be carefully reevaluated pathologically.

Ryuichi TANAKA, M.D. Department of Neurosurgery Brain Research Institute Niigata University Niigata, Japan
Oka and Scheithauer describe a precise review of clinico-pathological features of atypical teratoid/rhabdoid tumor. They collected their own 15 cases and another 118 reported cases. Meta-analysis of these cases confirmed poor prognosis of this tumor occurring at less than 2 years of age. The tumor is histologically distinctive, genetically interesting with monosomy 22, and with poor clinical outcome.

Recently, I experienced surgery of this tumor occurring in a two-year-old child (unpublished observation). The tumor was reddish-gray, but it was not bloody and easy to remove. Postoperative MRI showed subtotal removal of the tumor, and whole brain irradiation followed. However, the tumor recurred within a month showing dissemination into the cerebrospinal fluid, and the child died 5 months post surgery. The profile of this child is a typical example of this tumor as the authors described in the result and discussion. The tumor has a worse prognosis than medulloblastoma or primitive neuroectodermal tumor. Early diagnosis and proper treatment including chemotherapy are needed.

Kazuo YaMADA, M.D. Department of Neurosurgery Nagoya City University Medical School Nagoya, Japan 